Hydrol. Earth Syst. Sci., 15, 1853-1863, 2011

www.hydrol-earth-syst-sci.net/15/1853/2011/

doi:10.5194/hess-15-1853-2011

(C) Author(s) 2011. CC Attribution 3.0 License.

\title{
The geomorphic structure of the runoff peak
}

\author{
R. Rigon ${ }^{1}$, P. D'Odorico ${ }^{2}$, and G. Bertoldi ${ }^{3}$ \\ ${ }^{1}$ Dipartimento di Ingegneria Civile e Ambientale and CUDAM, Universitá di Trento, Via Mesiano 77, Trento, Italy \\ ${ }^{2}$ Department of Environmental Sciences, University of Virginia, 291 McCormick Road, P.O. Box 400123, Charlottesville, \\ VA 22904-4123, USA \\ ${ }^{3}$ Institute for Alpine Environment, EURAC Research, Viale Druso 1, Bolzano, Italy \\ Received: 23 December 2010 - Published in Hydrol. Earth Syst. Sci. Discuss.: 24 January 2011 \\ Revised: 10 May 2011 - Accepted: 25 May 2011 - Published: 17 June 2011
}

\begin{abstract}
This paper develops a theoretical framework to investigate the core dependence of peak flows on the geomorphic properties of river basins. Based on the theory of transport by travel times, and simple hydrodynamic characterization of floods, this new framework invokes the linearity and invariance of the hydrologic response to provide analytical and semi-analytical expressions for peak flow, time to peak, and area contributing to the peak runoff. These results are obtained for the case of constant-intensity hyetograph using the Intensity-Duration-Frequency (IDF) curves to estimate extreme flow values as a function of the rainfall return period. Results show that, with constant-intensity hyetographs, the time-to-peak is greater than rainfall duration and usually shorter than the basin concentration time. Moreover, the critical storm duration is shown to be independent of rainfall return period as well as the area contributing to the flow peak. The same results are found when the effects of hydrodynamic dispersion are accounted for. Further, it is shown that, when the effects of hydrodynamic dispersion are negligible, the basin area contributing to the peak discharge does not depend on the channel velocity, but is a geomorphic propriety of the basin. As an example this framework is applied to three watersheds. In particular, the runoff peak, the critical rainfall durations and the time to peak are calculated for all links within a network to assess how they increase with basin area.
\end{abstract}

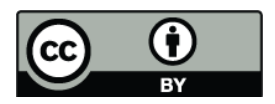

Correspondence to: R. Rigon (riccardo.rigon@ing.unitn.it)

\section{Introduction}

A number of hydrological analyses require the evaluation of the highest peak-flow values expected to occur with a given return period. Most of the methods addressing this issue from the simple rational method Mulvaney (1851), Doodge (1957) to the use of distributed rainfall-runoff models (e.g., Beven, 2001) - have been developed with the purpose of providing quantitative predictions of peak flows for engineering applications more than a synthesis of their dependence on the geomorphic and hydrodynamic characteristics of the watershed. To this end, this paper develops a simplified theory based on the concepts of geomorphologic instantaneous unit hydrograph (GIUH) and of width function (Rinaldo et al., 1991, 1995; D'Odorico and Rigon, 2003). This theory extends the results of Henderson (1963) and Meynink and Cordery (1976) and complements some findings by Robinson and Sivapalan (1997).

In this paper we analyze the critical rainfall duration for linear systems as, for instance, in Fiorentino et al. (1987) and Iacobellis and Fiorentino (2000) who found that the flow peak has a linear dependence on the rainfall excess intensity over a duration equalling the IUH lag-time. Our study provides a geomorphic interpretation of these previous results. To this end, we use the framework of the GIUH theory to determine the rainfall duration that causes the highest peak flow.

The goals of the paper include: understanding the geomorphic structure of the highest peak-flow caused by rainfall with given return period; redefining the concept of concentration time within the framework of the GIUH theory; determining the duration of the rainfall able to generate the maximum peak flow under the assigned climatic conditions; determining the time to peak as a function of rainfall and basin characteristics.

Published by Copernicus Publications on behalf of the European Geosciences Union. 


\subsection{Basic concepts and results}

The concept of Unit Hydrograph (Sherman, 1932) is used in the representation of the hydrograph as a sum of the responses to different rainfall inputs observed throughout an individual rainstorm

$Q(t)=A_{\mathrm{T}} \int_{0}^{t} f(t-\tau) p(\tau) d \tau$

with $A_{\mathrm{T}}$ being the total contributing area, $t$ the time, $\tau$ the time counted starting at the beginning of the rainstorm, $p$ the intensity of effective precipitation at time $\tau$, and $f(t)$ the instantaneous unit hydrograph (IUH). The IUH represents the travel time probability density function of a unit amount of water instantaneously injected into the basin (Gupta and Mesa, 1988); $f(t)$ can be determined either through some simple conceptual frameworks e.g. (Nash, 1957) or through the geomorphological theory (Rodriguez-Iturbe and Valdes, 1979; Gupta et al., 1980). Depending on the physical hypotheses underlying the different formulations of the IUH, $f(t)$ can be defined either within an infinite or a finite time domain. In the latter case $f(t)=0$ for $t \geq \tau_{\mathrm{c}}$, where $\tau_{\mathrm{c}}$ is the concentration time of the rational method (i.e. the time at which the whole basin contributes to the discharge at the outlet).

The integral:

$S(t)=\int_{0}^{t} f(\tau) d \tau$

is known in literature as $S$-hydrograph (e.g., Doodge, 2003, p. 86) and represents the cumulative probability distribution of travel times inside the basin $\left(S(t)=1\right.$ for $\left.t \geq \tau_{\mathrm{c}}\right)$, and $S(t)$ can be interpreted as the ratio between contributing area at time $t$ and basin area, since $A_{\mathrm{T}}$ in Eq. (1) is the total contributing area.

In this simplified approach the rate of (effective) precipitation is assumed to be constant throughout individual rainstorms of duration $t_{\mathrm{p}}$ :

$p\left(t, t_{\mathrm{p}}\right) \equiv p H\left(t_{\mathrm{p}}-t\right) H(t)$,

where $H()$ is the Heaviside step function (i.e. $H(t)=1$ for $t \geq 0$ and $H=0$ otherwise). By definition, $p$ can be considered the expected value of the effective intensity of rainfall during the storm. In what follows we will refer to the expected value of $p$ as a first-order approximation of the "real" storm hyetograph. This approach will allow us to obtain semi-analytical results that could be easily generalized to the case of hyetographs with non-constant intensity as suggested by D'Odorico et al. (2005) for the case of landslidetriggering precipitation.

The time-to-peak, $t^{*}$, can be found by solving the following equation, first derived by Henderson (1963) and hereafter called Henderson's equation (see also Appendix A):

$f(t)=f\left(t-t_{\mathrm{p}}\right) \quad t_{\mathrm{p}} \leq \tau_{\mathrm{c}}$.
The graphic solution of Eq. (4) is illustrated in Fig. 1. For $t>\tau_{\mathrm{c}}, S(t)$ is a constant (hence, $f(t)=d S(t) / d t=0$ ), while $S\left(t-t_{\mathrm{p}}\right)$ is an increasing function of $t$ (i.e. $f\left(t-t_{\mathrm{p}}\right)>0$ ). Therefore the solution, $t^{*}$, of Eq. (4) needs to be searched in the interval $\left[t_{\mathrm{p}}, \tau_{\mathrm{c}}\right]$. Figure 1, shows the existence of a delay, $\left(\Delta t=t^{*}-t_{\mathrm{p}}\right)$, between the end of the rainstorm and the occurrence of the flow peak. This delay depends on the characteristics of the IUH and its parameters. The delay, $\Delta t$, corresponding to the main (i.e. highest) peak can be easily determined: for example, in the case of the catchment discussed in Sect. 3, $\Delta t$ is a decreasing function of $t_{\mathrm{p}}$ and becomes null as $t_{\mathrm{p}}$ approaches $\tau_{\mathrm{c}}$ (Fig. 2). Moreover, Fig. 2 shows that for small values of $t_{\mathrm{p}}$ multiple peak flows - corresponding to secondary maxima - may occur. Henderson (1963) and Robinson and Sivapalan (1997) solved Eq. (4) using a triangular hydrograph. However it can be solved analytically (Appendix B) in the case of Nash hydrograph (Nash, 1957) and with simple numerical code in the general case, as explained in the following section.

If $t^{*}$ is the time to peak - counted from the beginning of the rainfall - the peak flow, $Q_{\mathrm{p}}$, is then estimated as $Q\left(t^{*}\right)$ using Eq. (A5) for the case of hyetographs with constant intensity:

$Q_{\mathrm{p}}\left(t^{*}\right)= \begin{cases}p A_{\mathrm{T}}\left(S\left(t^{*}\right)-S\left(t^{*}-t_{\mathrm{p}}\right)\right)=p A^{*} 0 \leq t_{\mathrm{p}} \leq \tau_{\mathrm{c}} \\ p A_{\mathrm{T}} S\left(\tau_{\mathrm{c}}\right)=p A_{\mathrm{T}} & t_{\mathrm{p}}>\tau_{\mathrm{c}}\end{cases}$

with $t^{*}$ being a function of $t_{\mathrm{p}}$ (through Eq. 4) and $S\left(t^{*}\right)$ the fraction of contributing area at $t=t^{*}$. If the duration is smaller than the concentration time, the contributing area at $t=t^{*}$ is $A^{*}=A_{\mathrm{T}}\left[S\left(t^{*}\right)-S\left(t^{*}-t_{\mathrm{p}}\right)\right]$.

\subsection{Extreme values of peak flows}

The maximum peak flow occurring after a rainstorm with a certain return period, $t_{\mathrm{r}}$, (hereafter referred to as extreme peak flow) can be determined by expressing $p$ in Eq. (5) as a function of duration, $t_{\mathrm{p}}$, and return period, $t_{\mathrm{r}}$. These curves provide a statistical representation of the most severe rainfall conditions for a certain geographic location and return period. Thus, the extreme peak-flow discharge, $Q_{\mathrm{p}}$ (Eq. 5), depends on $t_{\mathrm{p}}$ also through $p$. Because for any given return period, $p=p\left(t_{\mathrm{p}} \mid t_{\mathrm{r}}\right)$ is a decreasing function of $t_{\mathrm{p}}$ and $S\left(t^{*}\right)=S\left(t_{\mathrm{p}}+\Delta t\right)$ is an increasing function of its argument, there is a particular rainfall duration, $t_{\mathrm{p}}^{*}$, which maximizes the peak-flow discharge. Such a duration needs to be shorter than (or equal to) the concentration time $\tau_{\mathrm{c}}$. This critical duration can be found by solving the equation $\mathrm{d} Q_{\mathrm{p}} / \mathrm{d} t_{\mathrm{p}}=$ $\mathrm{d} Q\left(t_{\mathrm{p}}+\Delta t\right) / \mathrm{d} t_{\mathrm{p}}=0$, where $\Delta t=\Delta t\left(t_{\mathrm{p}}\right)$ is a smooth function of $t_{\mathrm{p}}$. We will indicate with $\Delta t^{*}$ the value of $\Delta t\left(t_{\mathrm{p}}\right)$ calculated for $t_{\mathrm{p}}=t_{\mathrm{p}}^{*}$. The first order-derivative of Eq. (5a) becomes

$$
\begin{aligned}
\frac{d Q\left(t^{*}\right)}{d t_{\mathrm{p}}} & =A_{\mathrm{T}}\left\{p^{\prime}\left(t_{\mathrm{p}}^{*} \mid t_{\mathrm{r}}\right)\left[S\left(t_{\mathrm{p}}^{*}+\Delta t^{*}\right)-S\left(\Delta t^{*}\right)\right]\right. \\
& +p\left(t_{\mathrm{p}}^{*} \mid t_{\mathrm{r}}\right)\left[f\left(t_{\mathrm{p}}^{*}+\Delta t^{*}\right)\left(1+\Delta^{\prime}(t)\right)\right. \\
& \left.\left.-f\left(\Delta t^{*}\right) \Delta^{\prime}(t)\right]\right\}=0
\end{aligned}
$$



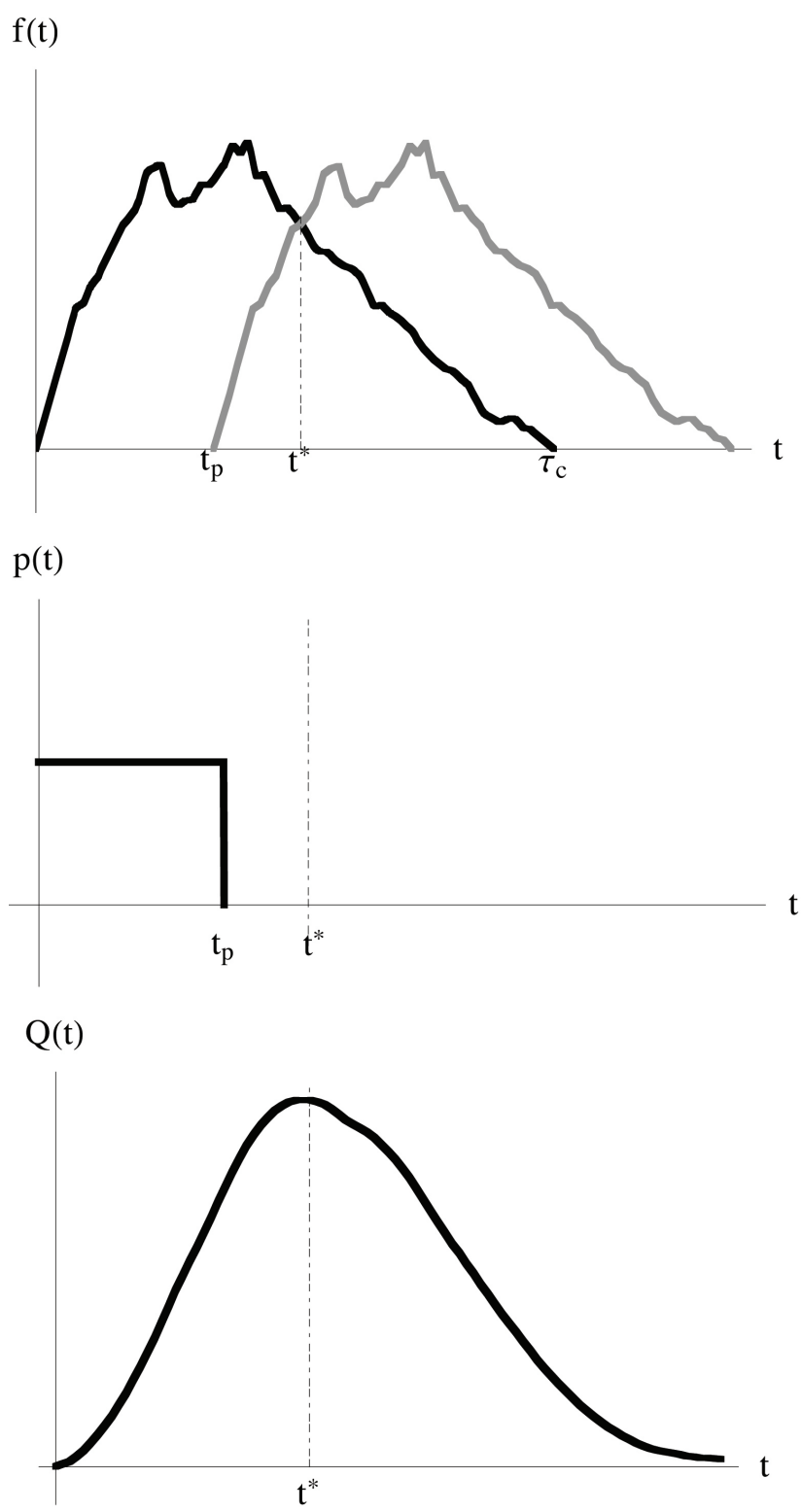

Fig. 1. The solutions of Eq. (4) are given by the crossing of the unit hydrograph $f(t)$ with another unit hydrograph, $f\left(t-t_{\mathrm{p}}\right)$, shifted by a distance, $t_{\mathrm{p}}$. The figure shows: (a) the graphical solution of the equation (in black $f(t)$ and in grey $\left.f\left(t-t_{\mathrm{p}}\right)\right)$; $t^{*}$ is the time to peak. (b) $t^{*}$ is usually larger than $t_{\mathrm{p}}$. This is true for constant intensity uniform hyetograph; (c) the discharge obtained by the convolution of the IUH in (a) with the rainfall in (b).

where $p^{\prime}\left(t_{\mathrm{p}}^{*} \mid t_{\mathrm{r}}\right)$ is the first-order derivative of the $p\left(t_{\mathrm{p}}^{*} \mid t_{\mathrm{r}}\right)$ with respect to $t_{\mathrm{p}}$ and the first-order derivative of $S(t)$ has been expressed as the IUH (i.e. $\left.S^{\prime}\left(t_{\mathrm{p}}+\Delta t\right)=f\left(t_{\mathrm{p}}+\Delta t\right)\right)$ ). Substituting Eq. (4) into Eq. (6) we obtain

$\frac{p^{\prime}\left(t_{\mathrm{p}} \mid t_{\mathrm{r}}\right)}{p\left(t_{\mathrm{p}} \mid t_{\mathrm{r}}\right)}=-\frac{f\left(t_{\mathrm{p}}+\Delta t\right)}{S\left(t_{\mathrm{p}}+\Delta t\right)-S(\Delta t)}$. which is equivalent to the main equation in Meynink and Cordery (1976), though it is here derived for any shape of the IUH. We use intensity-duration-frequency (IDF) curves to relate rainfall intensity. Scaling models of IDF curves are often based on power laws

$p\left(t_{\mathrm{p}} \mid t_{\mathrm{r}}\right)=a\left(t_{\mathrm{r}}\right) t_{\mathrm{p}}^{-m}$

where $a\left(t_{\mathrm{r}}\right)$ is a function of the return period $t_{\mathrm{r}}$ and $0 \leq m \leq 1$ is independent of $t_{\mathrm{r}}$. Equation (8) in Eq. (7) gives

$m=\frac{t_{\mathrm{p}} f\left(t^{*}\right)}{S\left(t^{*}\right)-S\left(\Delta t^{*}\right)} \equiv g\left(t_{\mathrm{p}}^{*}\right)$

where $t^{*}=t_{\mathrm{p}}^{*}+\Delta t^{*}$. Because the dependence on $t_{\mathrm{r}}$ in Eq. (8) is through $a\left(t_{\mathrm{r}}\right)-$ which does not appear in Eq. (9) - Eq. (9) implies that, according to this linear theory of the hydrologic response, the critical rainfall duration $\left(t_{\mathrm{p}}^{*}\right)$ associated with extreme runoff peak flow values, is independent of the return period. The same result applies also to the case of self- similar design storm hyetograph (e.g., Burlando and Rosso, 1996) and to the design storm hyetograph suggested in Hershfield (1961) and commonly used in the engineering practice in the US since Bell (1969).

The solution of the set of Eqs. (9) and (4) can be used to determine the critical rainfall duration, $t_{\mathrm{p}}^{*}$, and the time to peak, $t^{*}$. It can be shown that $g(0)=1$ and $g(\infty)=0$, consistently with the common observation that values of $m$ span the interval $[0,1]$ ( $m$ ranges most commonly between 0.5 and 1). Depending on the rainfall duration $t_{p}$ and on the shape of the IUH, for some values of $m$, it is possible to have multiple solutions of Eq. (9), which correspond to local minima or maxima of discharge, as shown on a case study in Section 3

Once $t_{\mathrm{p}}^{*}$ is known from Eq. (9), Eq. (5) provides the maximum discharge under a rainfall of assigned return period, $t_{\mathrm{r}}$, as

$Q_{\operatorname{MAX}}\left(t_{\mathrm{r}}\right)=p\left(t_{\mathrm{p}}^{*} \mid t_{\mathrm{r}}\right) C\left(t^{*}, t_{\mathrm{p}}^{*}\right) A_{\mathrm{T}}$

where $C\left(t^{*}, t_{\mathrm{p}}^{*}\right) \equiv S\left(t^{*}\right)-S\left(t^{*}-t_{\mathrm{p}}^{*}\right)$. We notice that Eq. (10) is similar to the well known rational method equation Chow et al. (1988); however, the runoff coefficient, $C$, depends on the effective fraction of contributing area evaluated as a function of time to peak, $t^{*}$, and on the critical rainfall duration, $t_{\mathrm{p}}^{*}$ (Eq. 6), rather than on the concentration time. The total contributing area, $A_{\mathrm{T}}$, can be determined as explained in the following section. We note that in the rational method the coefficient $C$ accounts for effects of "within-storm" rainfall variability, runoff-generation (i.e., $C$ is a runoff coefficient), and runoff routing. Our approach explains only the dependence of $C$ on routing processes, while the effects of "within-storm" rainfall patterns are not investigated. We also note that, unlike the rational method, our theory does not assume values of contributing area and rainfall duration. Rather, both $A_{\mathrm{T}}$ and $t_{\mathrm{p}}^{*}$ are the outcome of the 


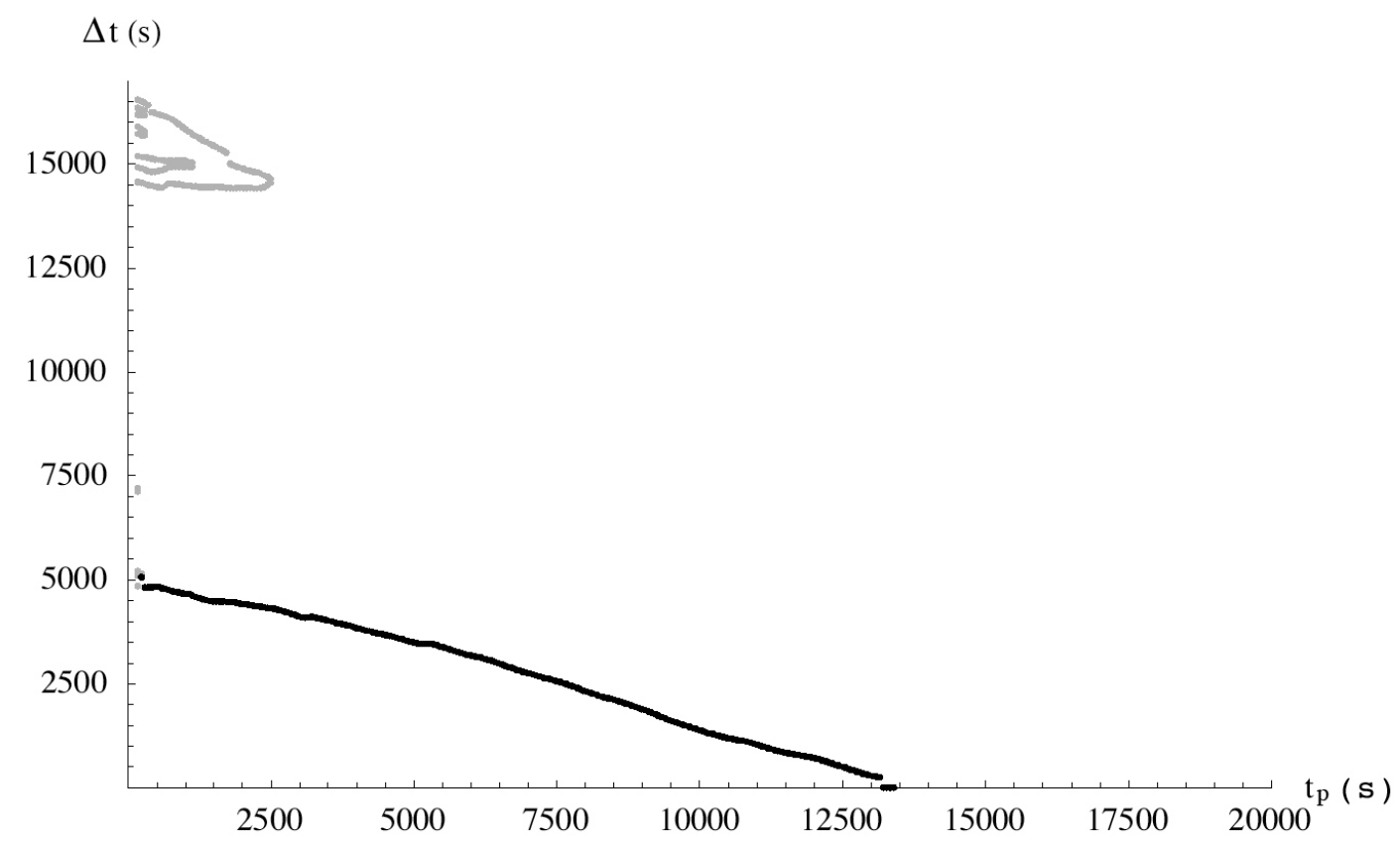

Fig. 2. Delay, $\Delta t$, of time to peak with respect to the end of the rainstorm, as a function of rainfall duration, $t_{\mathrm{p}}$, for the case study of Longo watershed (Italy), illustrated in detail Paragraph 3. $\Delta t$ is a decreasing function of $t_{\mathrm{p}}$ and for values $t_{\mathrm{p}} \geq \tau_{\mathrm{c}}$, the delay is null. For smaller $t_{\mathrm{p}}$ multiple peak flows are possible. The grey points correspond to secondary peak flows and the black points to the largest peak flow.

interplay of basin and climatic characteristics, and are calculated as values associated with the maximum peak flows.

\section{The geomorphological analysis of runoff peaks}

The geomorphological theory of the hydrologic response (Rodriguez-Iturbe and Valdes, 1979; Gupta et al., 1980; Rinaldo et al., 1991; Rinaldo and and Rodriguez-Iturbe, 1996) provides an interpretation of the IUH, based on the basin morphology and simple dynamical assumptions. In this paper we express the Geomorphologic Instantaneous Unit Hydrograph (GIUH) through a generalization of the width function, $W(x)$, (e.g., Shreve, 1969; Kirkby, 1986; Gupta and Mesa, 1988; Brutsaert, 2005). $W(x)$ is the probability distribution of distances, $x$ (measured along the network), between any point in the basin and the outlet. In recent years a number of studies have recognized the soundness of this approach, strengthened its theoretical bases (Rinaldo et al., 1991, 1995; Saco and Kumar, 2002a,b; D'Odorico and Rigon, 2003; Botter and Rinaldo, 2003) and shown its applicability and calibration to small and large catchments (e.g., Naden, 1992; Snell and Sivapalan, 1994; Franchini and O'Connell, 1996; Da Ross and Borga, 1997; Naden et al., 1999; Yang et al., 2002; Brutsaert, 2005).

The basin-scale travel time distribution, $f(t)$, can be expressed as a function of $W(x)$

$f(t)=\int_{0}^{L} W(x) f(t \mid x) d x$ where $f(t \mid x)$ is the travel time distribution in a path of length $x$, and $L$ is the length of the longest drainage path.

\subsection{The kinematic case}

When the effects of hydrodynamic dispersion are negligible, water is subject mainly to advection (kinematic wave), and the probability distribution of travel times, $f(t \mid x)$, for the rain falling at a distance $x$ (measured along the flow path) from the outlet is

$f(t \mid x)=u \delta\left(t-\frac{x}{u}\right)$

with $u$ being the flood wave celerity and $\delta()$ the Dirac deltafunction. Hence, Eq. (12) in Eq. (11) gives:

$f(t)=u W(u t)$.

In this framework, which generalizes Ross (1921), the concentration time is rigourously $\tau_{\mathrm{c}}=L / u$, with $L$ being the longest drainage path. When the IDF curves are expressed by Eq. (8) and $f(t)$ by Eqs. (13), (4) and (9) become:

$$
\begin{aligned}
W(u t) & =W\left(u\left(t-t_{\mathrm{p}}\right)\right) . \\
m & =\frac{u t_{\mathrm{p}} W\left(u\left(t_{\mathrm{p}}+\Delta t\right)\right)}{\left(S\left(t_{\mathrm{p}}+\Delta t\right)-S(\Delta t)\right)}
\end{aligned}
$$

Equation (14) provides the lag $\Delta t=t^{*}-t_{\mathrm{p}}$ between the end of the storm and the peakflow occurrence, while Eq. (15) gives the critical rainfall duration, $t_{\mathrm{p}}^{*}$. As noted before, $t_{\mathrm{p}}^{*}$ is independent of $t_{\mathrm{r}}$. When Eqs. (14) and (15) are solved for 
different values of the parameter $u$, the drainage area contribution to the peak flow, $A^{*} \equiv A_{\mathrm{T}}\left(S\left(t^{*}\right)-S\left(t^{*}-t_{\mathrm{p}}\right)\right)$, does not change. As shown in Figure $3, f(t)$ shrinks in width as $u$ increases, but at the same time it increases in height, maintaining a constant area, $A^{*} \equiv A_{\mathrm{T}}\left(S\left(t^{*}\right)-S\left(t^{*}-t_{\mathrm{p}}\right)\right)$.

The maximum peak discharge depends hyperbolically on rainfall durations (and flow velocity):

$Q_{\mathrm{MAX}}=a\left(t_{\mathrm{r}}\right)\left(t_{\mathrm{p}}^{*}\right)^{-m} C\left(t^{*}, t_{\mathrm{p}}^{*}\right) A_{\mathrm{T}}=a\left(t_{\mathrm{r}}\right)\left(t_{\mathrm{p}}^{*}\right)^{-m} A^{*}$.

Equation (13) provides a model of IUH which depends only on the parameter $u$ and on the basin morphology (i.e. on the shape of the width function). Because $A^{*}$ is independent

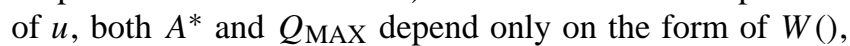
i.e. on the structure of the flow paths.

\subsection{The effect of diffusive wave propagation}

The analysis presented in the previous section accounts for the mean and most of the variance of the unit hydrograph (e.g., D'Odorico and Rigon, 2003). However, it does not include the effects of hydrodynamic dispersion which introduces a smoothing on the peak flows. In this case flood routing can be expressed by a parabolic differential equation which is obtained either as a diffusive-wave approximation of the de Saint-Venant equations, or through the assumption that water parcels are subject to Wiener dynamics, superimposed to the deterministic advection discussed in the previous sections. This assumption leads to the estimation of the travel time distribution as a solution of the Kolmogorov's backward Eq. (Mesa and Mifflin, 1986) with suitable boundary conditions. Thus, the probability distribution of travel times is expressed by the Gaussian inverse function (Rinaldo et al., 1991), defined now for $t \in[0, \infty]$

$f(t \mid x)=\frac{x}{\sqrt{4 \pi D t^{3}}} \exp \left[-\frac{(x-u t)^{2}}{4 D t}\right]$

where $D$ is the coefficient of hydrodynamic dispersion; the kinematic case (Eq. 12) is obtained for $D \rightarrow 0$.

In this case the hydrograph can be expressed (see Eq. C2 in Appendix C) as

$$
\begin{aligned}
& \frac{Q(t)}{A_{\mathrm{T}} p\left(t_{\mathrm{p}}, t_{\mathrm{r}}\right)}= \\
& \begin{cases}\int_{0}^{L} d x W(x) \Theta(t \mid x) & \text { if } 0 \leq t \leq t_{\mathrm{p}} \\
\int_{0}^{L} d x W(x)\left[\Theta(t \mid x)-\Theta\left(t-t_{\mathrm{p}} \mid x\right)\right] & \text { if } t>t_{\mathrm{p}},\end{cases}
\end{aligned}
$$

where

$$
\begin{gathered}
\Theta(t \mid x)=\frac{1}{2} \operatorname{Erfc}\left(\frac{x}{2 \sqrt{t D}}-\frac{u}{2} \sqrt{\frac{t}{D}}\right)+\frac{1}{2} \operatorname{Exp}\left(\frac{u x}{D}\right) \\
\operatorname{Erfc}\left(\frac{x}{2 \sqrt{t D}}+\frac{u}{2} \sqrt{\frac{t}{D}}\right) .
\end{gathered}
$$

Notice that $d \Theta(t \mid x) / d t=f(t \mid x)$ with $f(t \mid x)$ given by Eq. (17); therefore, for $t \geq t_{\mathrm{p}}$, Henderson's equation can be written as

$$
\int_{0}^{L} d x W(x)\left[f(t \mid x)-f\left(t-t_{\mathrm{p}} \mid x\right)\right]=0 .
$$

The time $t^{*}$ satisfying Eq. (20) is always larger than the precipitation duration as in the case discussed in Sect. 2. The other results developed in the previous section can be extended to the case $D>0$, once the function $W(u t)$ in Eqs. (13), (14) and Eq. (15) is replaced by

$\omega(t) \equiv \int_{0}^{L} W(x) f(t \mid x) d x$.

Thus, the critical rainfall time $t_{p}^{*}$ can be calculated by inserting Eq. (21) into Eqs. (14) and (15). It is found that the area, $A^{*}$, contributing to the flow peak is independent of the return period. However, when $D$ assumes large values $\left(\sim 1000 \mathrm{~m}^{2} \mathrm{~s}^{-1}\right)$, it can be shown that $A^{*}$ depends on $D$, the shape of $W(x)$, and on $u$.

The peak discharge can be obtained numerically by substituting the time to peak, $t^{*}$, into Eq. (18). Interestingly, the concept of concentration time, used in the non-diffusive (kinematic) framework, would be meaningless in this case because the domain of $\omega(t)$ and $f(t \mid x)$ are infinite. However, it can be here re-introduced as a stochastic variable, $\hat{\tau}_{\mathrm{c}}$ with distribution given by Eq. (17). In fact, in the case $D \neq 0$, after a time $\tau_{\mathrm{c}}=L / u$ has elapsed from the beginning of the rainstorm, the furthermost portions of the basin may still contribute to the hydrologic response with probability smaller than 1 .

\section{Case study}

An application of the theory developed in this paper, was carried out for the cases of the Longo watershed, a small alpine catchment $\left(A=10.3 \mathrm{~km}^{2}\right)$ within the Avisio basin $\left(A=469 \mathrm{~km}^{2}\right)$ at Predazzo (Italy) and of the Salt River in California (USA) $\left(A=2020 \mathrm{~km}^{2}\right)$.

In this application the width function was calculated differentiating for the velocities in channels, $u_{c}$, and in hillslopes, $u_{h}$, (Rinaldo et al., 1995; D'Odorico and Rigon, 2003), and introducing a rescaled-width function, $W^{\prime}\left(x^{\prime}\right)$, which is defined by measuring the length of the drainage paths as sum of the portion inside the river network, $x_{c}$, and that across the hillslope, $x_{h}$, with the latter being amplified by a factor $r=u_{c} / u_{h}$

$x^{\prime}=x_{c}+r x_{h}$.

The geomorphologic unit hydrograph can be thus expressed as

$f(t)=\frac{1}{\sqrt{4 \pi D t^{3}}} \int_{0}^{L} x^{\prime} W^{\prime}\left(x^{\prime}\right) e^{-\left(x^{\prime}-u_{c} t\right)^{2} / 4 D t} d x^{\prime}$ 


\section{$\mathrm{u} \mathrm{W}(\mathrm{u} \times \mathrm{t}) \times 10^{-5}$}

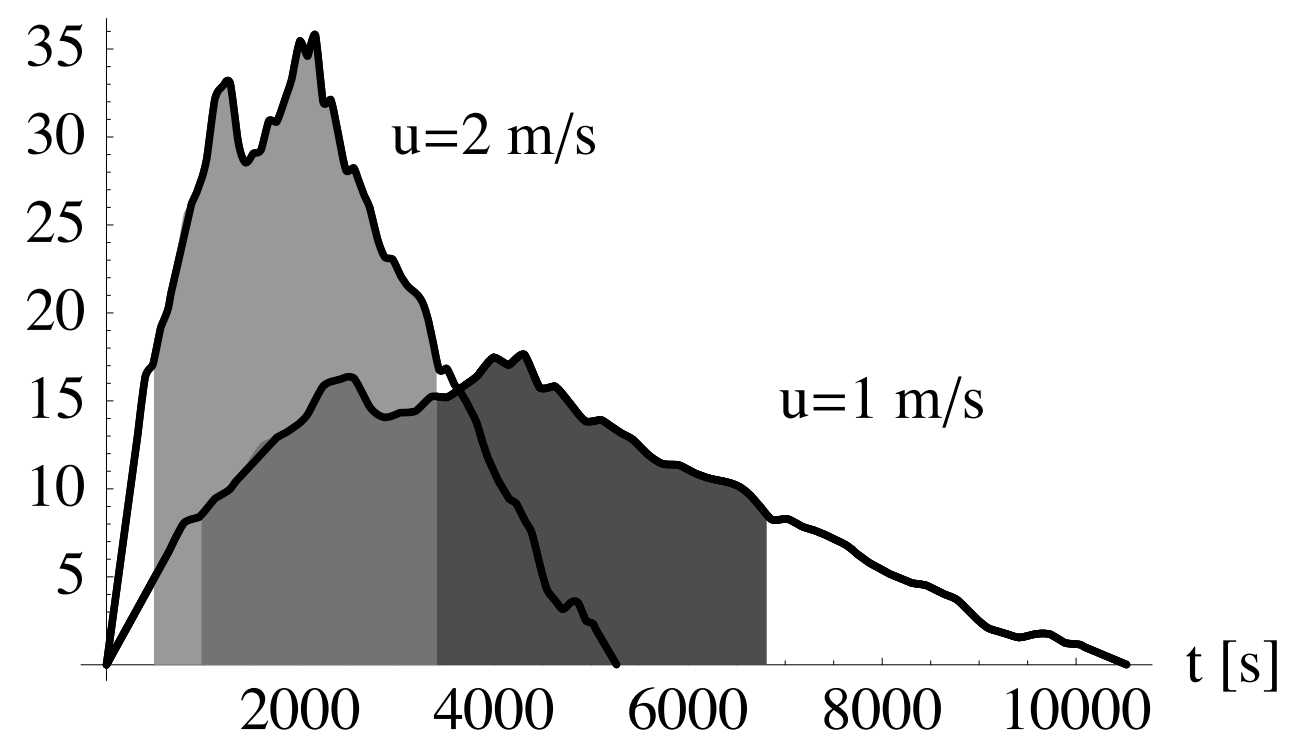

Fig. 3. Two examples unit hydrographs derived from the width function with $u=2 \mathrm{~m} \mathrm{~s}^{-1}$ (with higher peak on the left) and $u=1 \mathrm{~m} \mathrm{~s}$ (with smaller peaks on the right). The area contributing to the maximum discharge, as derived from the Henderson's equation and Eq. (17), is $80 \%$ of the total contributing area for each of the hydrograph and marked in grey (darker for the case $u=1$ and of an intermediate tone for both the cases). In the $u=1 \mathrm{~m} \mathrm{~s}^{-1}$ case, the rainfall duration which gives $\left(Q_{1}\right)_{\mathrm{MAX}}=14 \mathrm{~m}^{3} \mathrm{~s}^{-1}$ is $\left(t_{1}\right)_{\mathrm{p}}^{*}=5828 \mathrm{~s}$; is also $\left(t_{1}\right)^{*}=6808 \mathrm{~s}$ (the right limit of the grey). In the case $u=2 \mathrm{~m} \mathrm{~s}^{-1}$ it is: $\left(Q_{2}\right)_{\mathrm{MAX}}=21.2 \mathrm{~m}^{3} \mathrm{~s}^{-1},\left(t_{2}\right)_{\mathrm{p}}^{*}=2914 \mathrm{~s},\left(t_{2}\right)^{*}=3404 \mathrm{~s}$.

using the rescaled width function to express the probability distribution of drainage paths as if it was in a fictitious network where flood waves propagate at constant velocity, $u_{c}$.

Furthermore, different moisture conditions (D'Odorico and Rigon, 2003) are expressed through the quantiles, $q$, of a wetness index distribution (Beven and Kirkby, 1979; Barling et al., 1994), which defines the parts of the basins contributing to the hydrograph as saturation overland flow (e.g., Sivapalan et al., 1987; Beven and Wood, 1993; Woods and Sivapalan, 1997, 1999). Thus, the total contributing area, $A_{\mathrm{T}}$, is a function of the degree of saturation of the watershed, $A_{\mathrm{T}}=q A_{\mathrm{b}}$, where $A_{\mathrm{b}}$ is the basin area; the width function is calculated using only the saturated part of the basins (and not the whole basin area) and depends on the channel velocity, $u_{c}$, the scale parameter $r$ and the saturated fraction, $q$, of the basin, while the area contributing to the peak flow, $A^{*}$, depends also on $q$.

Figure 4 provides the graphical solution (i.e., $t_{\mathrm{p}}^{*}$ ) of Eq. (9), for the case of the Longo basin, where $D=0$, and for the value of the IDF curve $m=0.63$, found by analyzing the extreme precipitation in the area. It illustrates a typical dependence of $g\left(t_{\mathrm{p}}\right)$ on $t_{\mathrm{p}}$ (with $\Delta t\left(t^{*}\right)$ given by Eq. 4). The non-monotonic decrease makes clear the possibility to have multiple solutions of Eq. (9), which correspond to local minima or maxima of discharge. The Figure shows also how by increasing the velocity the time to peak decreases and the peak discharge increases. However the area contributing to the peak flow remains constant.
Table 1 reports the values of the variables $\tau_{\mathrm{c}}, t^{*}, t_{\mathrm{p}}^{*}, A^{*}$ and $Q^{*}$ in the Longo basin for different values of the saturated fraction of the basin. It is observed that $\tau_{\mathrm{c}}$, non-linearly increases with increasing values of $q$. It is also observed that $t^{*}$ is usually less than half $\tau_{\mathrm{c}}$. This difference is due to the long tails of the width function (D'Odorico and Rigon, 2003). The area contributing to the peak is about eighty per cent of the total saturated area, $A_{\mathrm{T}}$, and this fraction remains almost constant with varying $q$, i.e. a first rough estimation gives:

$A^{*} \sim 0.8 A_{\mathrm{T}} \sim 0.8 q A_{\mathrm{b}}$

Excluding the lowest saturation conditions, the critical rainfall duration increases almost linearly with $q>20 \%$, while the delay $\Delta t^{*}$ of the maximum peak increases non-linearly.

Because of its simplicity, the flow peak analysis can be easily extended to estimate the runoff peak in all the channel network links inside a basin, providing a regionalization of peak flows. Figure 5a, b and c show an example for the Avisio basin. Figure 5a shows how the maximum discharge $Q_{\text {MAX }}$ (with rainfall return period, $t_{\mathrm{r}}=100 \mathrm{yr}$ ) at any link increases with the contributing area $A$, as:

$Q_{\operatorname{MAX}}(A) \approx 0.906 A^{0.984}$

where the discharge is in $\mathrm{m}^{3} \mathrm{~s}^{-1}$ and the contributing area in $\mathrm{km}^{2}$. In this case, the parameters $\left(q=30 \%, u_{\mathrm{c}}=\right.$ $2 \mathrm{~m} \mathrm{~s}^{-1}, r=100$ ) were derived from calibration on a few 


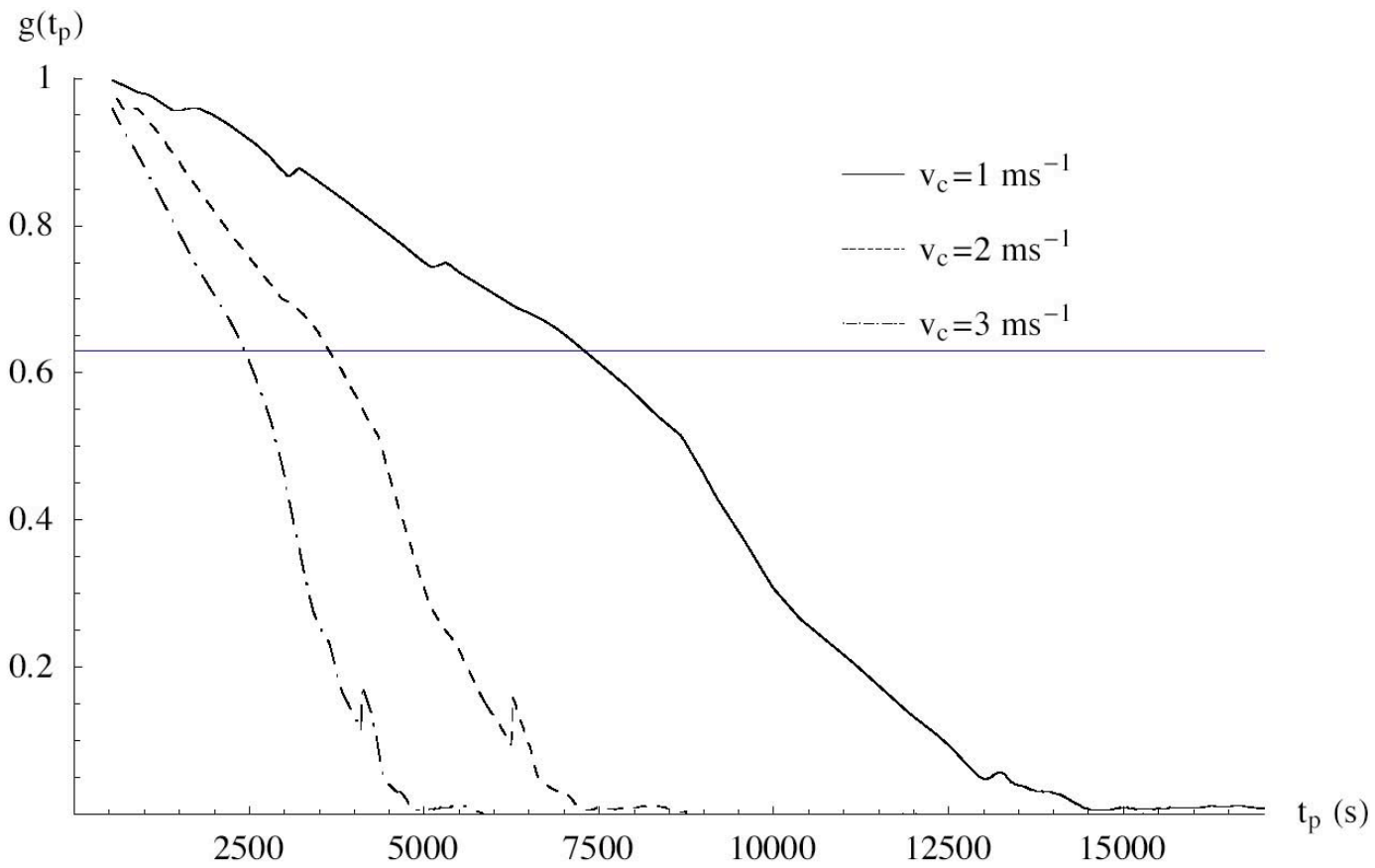

Fig. 4. Graphical solution of Eq. (9) for three values of channels celerity $u_{\mathrm{c}}$. The value of $m=0.63$ (horizontal line) is found by analysing the extreme precipitation in the area of the Longo watershed (Italy); the other curves represent the function $g\left(t_{\mathrm{p}}\right)$ given by Eq. (9) with different channel velocities. By increasing the velocity the time to peak decreases and the peak discharge increases. However the area contributing to the peak flow remains constant in all of the three cases.

Table 1. Relevant quantities calculated for the rescaled width functions of the Longo catchment $(r=10): q$ is the fraction of saturated areas; $t_{\mathrm{p}}^{*}$ is the duration of the rainfall which gives the largest peak discharge; $t^{*}$ the time to peak; $\tau_{\mathrm{c}}$ the concentration time; $A^{*}$ the area contributing to the peak; $Q^{*}$ is the largest discharge; $A_{\mathrm{T}}$ the total saturated area.

\begin{tabular}{rrrrrrr}
\hline & $\begin{array}{r}t_{\mathrm{p}}^{*} \\
(\mathrm{~s})\end{array}$ & $\begin{array}{r}t^{*} \\
(\mathrm{~s})\end{array}$ & $\begin{array}{r}\tau_{\mathrm{c}} \\
(\mathrm{s})\end{array}$ & $\begin{array}{r}A^{*} \\
\left(\mathrm{~km}^{2}\right)\end{array}$ & $\begin{array}{r}Q^{*} \\
\left(\mathrm{~m}^{3} \mathrm{~s}^{-1}\right)\end{array}$ & $\begin{array}{r}A_{\mathrm{T}} \\
\left(\mathrm{km}^{2}\right)\end{array}$ \\
\hline 0.05 & 4624 & 5075 & 14631 & 0.418 & 6.25 & 0.529 \\
0.13 & 5834 & 6808 & 15721 & 1.086 & 14 & 1.373 \\
0.28 & 6063 & 7632 & 16287 & 2.288 & 28.85 & 2.931 \\
0.55 & 6407 & 8325 & 16570 & 4.497 & 54.8 & 5.668 \\
0.82 & 6763 & 8884 & 17496 & 6.799 & 80.07 & 8.472 \\
1 & 7292 & 9925 & 17496 & 8.3171 & 94.012 & 10.33 \\
\hline
\end{tabular}

high-flow events (with approximatively 100 years of return period) measured for the largest sub-catchments of the Avisio. Clearly the discharges obtained are not representative of small basins $\left(A \leq 50 \mathrm{~km}^{2}\right)$, in which flow parameters and rainfall should be chosen differently. The heterogeneity of the responses shown in Fig. 5 for the small contributing areas is completely due to the different pathway lengths and their subdivision between hillslopes and channels. The maximum discharge at any link is due to rainfall of different duration as shown in Figure 5b. The critical duration is only weakly dependent on (i.e., increasing with) the area. For smaller contributing areas (indicated in the Figure as grey points) the critical rainfall duration is even more affected by the variability of the hillslope length. Even though data were not available to confirm the variability of $t_{\mathrm{p}}^{*}$ in the smaller basins, these results are consistent with those of Wood et al. (1990). Figure 5c shows the delay, $\Delta t$, of the time to peak with respect to rainfall duration as a function of the contributing areas. It is found that $\Delta t$ increases non-linearly with the contributing area. The flow peak is delayed with respect to the end of the rainstorm and this delay is larger in the larger subbasins.

The effect of the hydrodynamic dispersion is presented in Fig. 6a, which shows $t^{*}$ as a function of $t_{\mathrm{p}}$ in a mid-size basin (Salt River-CA, $2020 \mathrm{~km}^{2}$ ). Notice how $t^{*}$ is always larger than $t_{\mathrm{p}}$ when $t_{\mathrm{p}}<\tau_{\mathrm{c}}$ (in this basin $\tau_{\mathrm{c}}=\mathrm{L} / \mathrm{u}=11.2 \mathrm{~h}$ ), as opposed to the classic assumptions of the rational method that $t^{*}=t_{\mathrm{p}}$ when $t_{\mathrm{p}}<\tau_{\mathrm{c}}$. Because from Eq. (5) $Q_{\mathrm{p}} /\left(p A_{\mathrm{T}}\right)=A^{*} / A$, Fig. $6 \mathrm{~b}$ shows the portion of the watershed contributing to the basin response at the peak flow. It is observed that, with low values of the dispersion coefficient, the response is similar to the kinematic case and the contributing saturated source area is almost $A_{\mathrm{T}}$ (i.e. $A^{*} \approx A_{\mathrm{T}}$ ) when $t_{\mathrm{p}} \approx \tau_{\mathrm{c}}=11.2 \mathrm{~h}$. With relatively large values of $D$ (hence of the variance of travel times), $A^{*} / A_{\mathrm{T}}$ remains smaller than 1 in a broader interval of values of $t_{\mathrm{p}}$. The adimensional parameter $Q_{\mathrm{p}} /\left(p A_{\mathrm{T}}\right)$ is called in literature "the peakdeness" of the hydrograph 

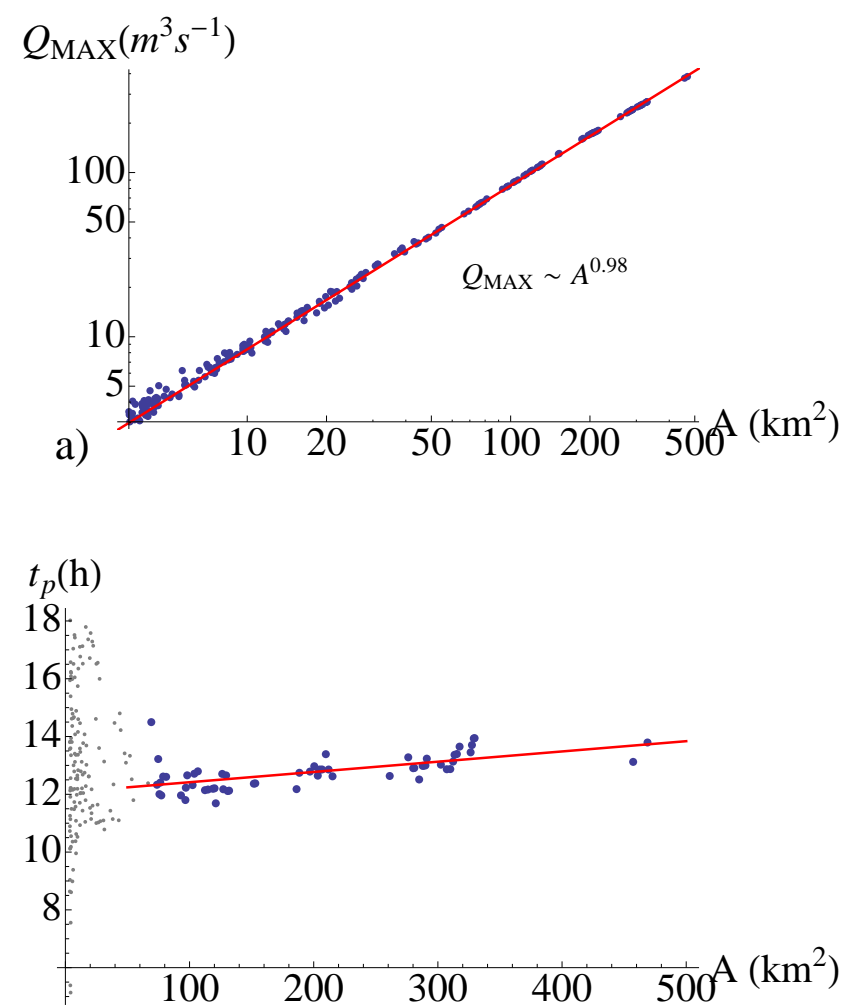

b)

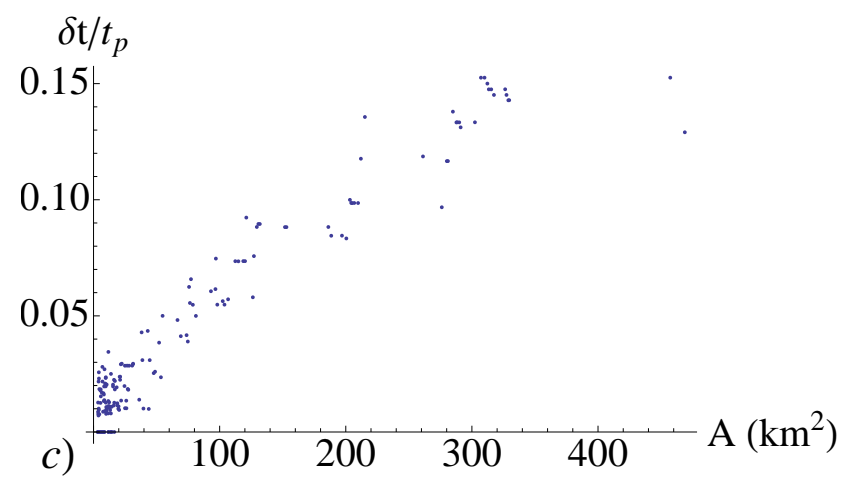

Fig. 5. (a) Plot of the peak discharge $Q_{\mathrm{MAX}}$ for all the links within the Avisio basin (Italy) as a function of contributing area. The parameters $\left(q=30 \%, u_{\mathrm{c}}=2 \mathrm{~m} \mathrm{~s}^{-1}, r=u / u_{\mathrm{h}}=100\right)$ were obtained from calibration on some real event in a few subcatchments and using IDF curves for a return period $t_{\mathrm{r}}=100 \mathrm{yr}$. (b) Critical rainfall duration, $t_{\mathrm{p}}^{*}$, of links ends inside the Avisio basin (Italy). For smaller contributing areas (indicated in the Figure as grey points) $t_{\mathrm{p}}^{*}$ and $Q_{\mathrm{MAX}}$ are affected by the variability of the hillslope length. (c) Delay of the time to peak with respect to the rainfall duration as a function of the contributing areas.

(Meynink and Cordery, 1976) and was found to vary in real cases between 0.5 and 1.5. Values larger than 1 must then be due to the variability of the rainfall and not to the basin geomorphology.
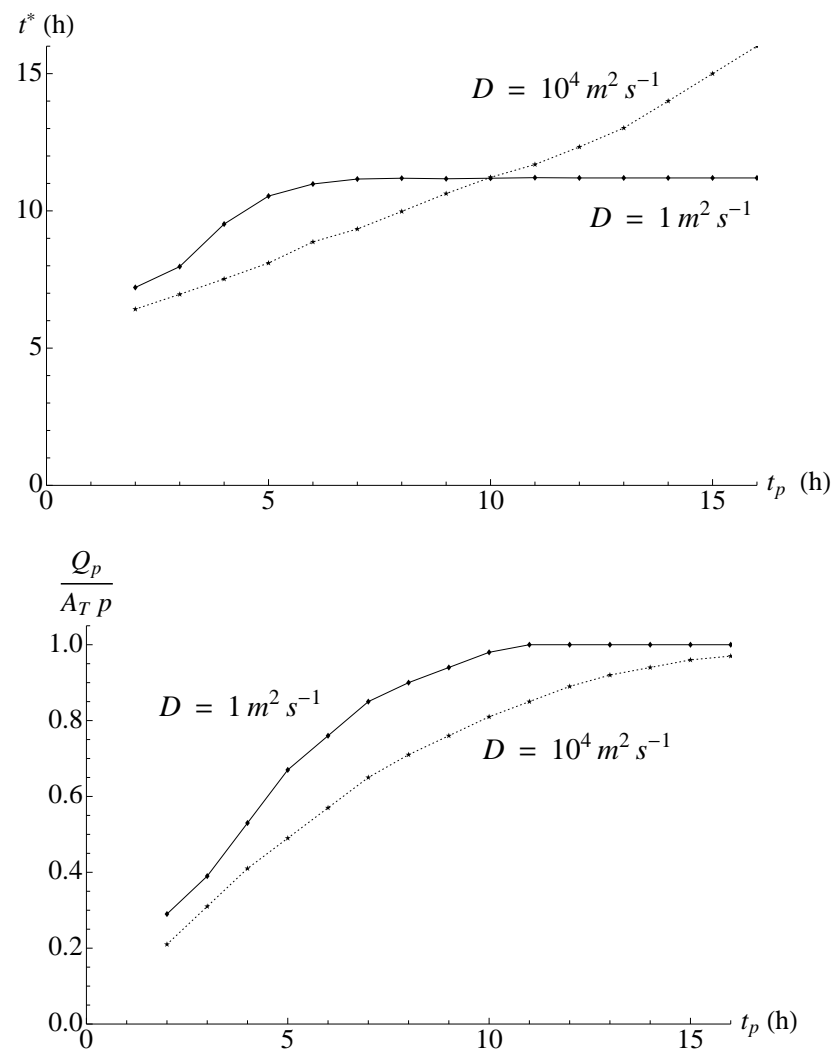

Fig. 6. (top) Time to peak $\left(t^{*}\right)$ and (bottom) normalized peak flow values as a function of the rainstorm duration $\left(t_{\mathrm{p}}\right)$ in the Salt River (CA).

\section{Conclusions}

The paper has developed a method for the evaluation of extreme peak-flows based on the theory of the instantaneous unit hydrograph and on the assumption that storm hyetographs have constant rainfall intensity. The system of two Eqs. (14) and (15) gives the maximum allowable discharge, $Q_{\mathrm{MAX}}$, produced by a precipitation event with a certain return period, $t_{\mathrm{r}}$, time to peak, $t^{*}=t_{\mathrm{p}}+\Delta t\left(t_{\mathrm{p}}\right)$ and constant intensity. When the intensity-duration dependence of extreme precipitation is expressed by a power law, $t_{\mathrm{p}}^{*}$ and $\Delta t$, and the area contributing to the peak do not depend on the return period. Analytical expressions of $\Delta t$ where obtained in particular for the linear reservoir and for the Nash models (in Appendix B).

These methods were also applied to the geomorphological IUH using the framework of the rescaled width function. It was found that, in the kinematic case, the area, $A^{*}$, contributing to extreme peak flows, $Q_{\mathrm{MAX}}$, does not depend on channel celerity but on the saturated fraction of the basin, $q$, the ratio between channel and hillslope velocities, $u_{\mathrm{c}} / u_{\mathrm{h}}$. When dispersion is introduced, the same area depends not only on dispersion $D$, also on the velocity in the channels. Thus, the extreme peakflow, $Q_{\mathrm{MAX}}$, is expressed through a framework 
that generalizes and clarifies the traditional expression of the rational method.

It was also shown that the peak discharge due to surface runoff increases almost linearly with the contributing area. Moreover, both the critical rainfall duration, $t_{\mathrm{p}}^{*}$, associated with maximum peakflow values, and the delay between $t_{\mathrm{p}}^{*}$ and the time-to-peak are increasing functions of the contributing area. The applicability of this framework is partly shown through a few basins with different sizes and morphologies. The semi-analytical character of the simplified theory allows for a fast estimation of the maximum discharge flowing in any link of the river network.

\section{Appendix A}

When $t<t_{\mathrm{p}}$ and the rainfall is given by Eq. (3) the rate of flow is:

$$
\begin{aligned}
Q(t) & =A_{\mathrm{T}} p \int_{0}^{t} f(t-\tau) d \tau=-A_{\mathrm{T}} p \int_{t}^{0} \mathrm{f}\left(t_{1}\right) d t_{1} \\
& =p A_{\mathrm{T}} S(t)
\end{aligned}
$$

where the change of variable in the integral is straightforward and $A(t) \equiv A_{\mathrm{T}} S(t)$ is the watershed area contributing to the flood discharge at time $t$ as follows from the definition of width function. For $t>t_{\mathrm{p}}$ we have instead:

$Q(t)=A_{\mathrm{T}} p \int_{0}^{t_{\mathrm{p}}} f(t-\tau) d \tau$

After the change of variable $t_{1}=t-\tau$ we obtain:

$$
\begin{aligned}
Q(t) & =-A_{\mathrm{T}} p \int_{t}^{t-t_{\mathrm{p}}} f\left(t_{1}\right) d t_{1} \\
& =A_{\mathrm{T}} p\left[\int_{0}^{t} f\left(t_{1}\right) d t_{1}-\int_{0}^{t-t_{\mathrm{p}}} f\left(t_{1}\right) d t_{1}\right]
\end{aligned}
$$

from which, we finally have:

$$
Q(t)=p A_{\mathrm{T}}\left[S(t)-S\left(t-t_{\mathrm{p}}\right)\right] .
$$

$Q(t)$ is a continuos function of $t$ at $t=t_{\mathrm{p}}$.

Thus, the basin response Eq. (1) can be expressed as

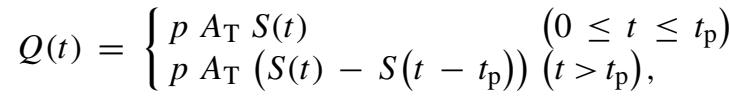

where $S(t)$ is the the S-hydrograph (Doodge, 2003). Notice that $S(t)$ is a continuos function of time and $Q(t)$ has a possible discontinuous derivative at $t=t_{\mathrm{p}}$. The maximum discharge is obtained at the time to peak, $t^{*}$, which is found by solving the equation $d Q / d t=0$ (Henderson, 1963):

$$
\begin{aligned}
& \frac{d S(t)}{d t}=f(t)=0 \quad 0 \leq t \leq t_{\mathrm{p}} \\
& \frac{d S(t)}{d t}=\frac{d S\left(t-t_{\mathrm{p}}\right)}{d t} \quad t>t_{\mathrm{p}}
\end{aligned}
$$

Notice that the solution of Eq. (A6) might not correspond to the actual maximum discharge. In fact, the maximum could occur in correspondence of the discontinuity point (i.e., $t^{*}=$ $t_{\mathrm{p}}$ ) in the first-order derivative of $Q(t)$ (see Equation (A5). Therefore, there is the need to check which one between the solution of Eq. (A6) and $t^{*}=t_{\mathrm{p}}$ corresponds to an actual maximum in $Q(t)$.

By definition in Eq. (A6a) $f(t)$ is null for $t^{*}=0-$ which represents a trivial and unphysical solution - or for $t^{*}=\tau_{\mathrm{c}}$. Thus, if $t_{\mathrm{p}}>\tau_{\mathrm{c}}$ the time to peak coincides with the concentration time, otherwise (i.e. for $t_{\mathrm{p}} \leq \tau_{\mathrm{c}}$ ) the solution is found by solving Eq. (A6b), which is equivalent to Eq. (4).

\section{Appendix B}

An interesting application of Henderson's equation is found for the case of the Nash IUH (Nash, 1957):

$f(t)=\frac{1}{n !}\left(\frac{t}{k}\right)^{n-1} e^{-t / k}$

where $n$ and $k$ are two calibration parameters. For $n=1$ the hydrograph is a negative exponential (linear reservoir) and the peak is at $t_{\mathrm{p}}$ (i.e. $t^{*}=t_{\mathrm{p}}$ ). For $n \geq 2$, Eq. (4) becomes

$\left(1-\frac{t_{\mathrm{p}}}{t}\right)^{n-1}=e^{-t_{\mathrm{p}} / k}$

which is solved as:

$t^{*}=\frac{t_{\mathrm{p}}}{1-\left(\exp \left(-t_{\mathrm{p}} / k\right)\right)^{1 /(n-1)}}$.

It is easy to observe that $t^{*}$ is always greater than $t_{\mathrm{p}}$ and that $t^{*}$ is an increasing function of the parameter $n$.

The resulting critical rainfall time is determined (Eq. 9) by solving:

$m=\frac{t_{\mathrm{p}}\left(t^{*}(n-1)\right) e^{t^{*} / k}}{\Gamma\left(n,\left(t^{*}-t_{\mathrm{p}}\right) / k\right)-\Gamma\left(n, t^{*} / k\right)}$

where $\Gamma$ is the incomplete gamma function:

$\Gamma(a, x)=\int_{0}^{\infty} t^{a-1} e^{-t} d t$

As noted, the linear-reservoir model ( $n=1$ case), is a particular case of Eq. (B2). In this case, $\Delta t=0$ for any $t_{\mathrm{p}}$. In this case Eq. (9) becomes

$m=\frac{\left(t_{\mathrm{p}} / k\right) e^{-t_{\mathrm{p}} / k}}{1-e^{-t_{\mathrm{p}} / k}}$. 


\section{Appendix C}

The hydrograph response is expressed by Eq. (1) with $p$ given by Eq. (3) and $f(t-\tau)$ by Eq. (11):

$$
\begin{array}{r}
Q(t)=A_{\mathrm{T}} p\left(t_{\mathrm{p}}, t_{\mathrm{r}}\right) \int_{0}^{t} H\left(t_{\mathrm{p}}-\tau\right) \\
\times \int_{0}^{L} W(x) f(t-\tau \mid x) d x d \tau .
\end{array}
$$

When $f(t-\tau \mid x)$ is expressed by Eq. (17), the change of variable $t-\tau \rightarrow t^{\prime}$ leads to

$$
\begin{aligned}
& \frac{Q(t)}{p\left(t_{\mathrm{p}}, t_{\mathrm{r}}\right) A_{\mathrm{T}}} \\
& =\left\{\begin{array}{c}
\int_{0}^{L} d x W(x) \int_{0}^{t} f\left(t^{\prime} \mid x\right) d t^{\prime} \\
=\int_{0}^{L} d x W(x) \Theta(t \mid x) \\
\text { for } 0 \leq t \leq t_{\mathrm{p}} \\
\int_{0}^{L} d x W(x) \int_{t-t_{\mathrm{p}}}^{t} f\left(t^{\prime} \mid x\right) d t^{\prime} \\
=\int_{0}^{L} d x W(x)\left[\Theta(t \mid x)-\Theta\left(t-t_{\mathrm{p}} \mid x\right)\right] \\
\text { for } t>t_{\mathrm{p}}
\end{array}\right.
\end{aligned}
$$

where

$$
\Theta(t)=\int_{0}^{t} f\left(t^{\prime} \mid x\right) d t^{\prime}=\mathcal{L}^{-1}\left[\frac{\hat{f}(s \mid x)}{s}\right]_{t^{\prime}=t} .
$$

In Eq. (C3) $\mathcal{L}^{-1}[]$ represents the inverse Laplace-transform, while $\hat{f}(s \mid x)$ is the Laplace transform of Eq. (17)

$$
\hat{f}(s \mid x)=\operatorname{Exp}\left[x \frac{u-\sqrt{u^{2}+4 s D}}{2 D}\right] .
$$

Equation (C4) in Eq. (C3) gives

$\Theta(t)=\operatorname{Exp}\left(\frac{u x}{2 D}\right) \mathcal{L}^{-1}\left[\frac{\operatorname{Exp}\left(-a \sqrt{s+b^{2}}\right)}{s}\right]$

where $a=x / \sqrt{D}$ and $b=u / 2 \sqrt{D}$. The inversion of the Laplace transform leads to Eq. (19).

Acknowledgements. We thank the two anonymous reviewers for having contributed to the improvement of the original manuscript with their valuable comments. The research was partially supported by the Italian Space Agency within the MORFEO project. Figures were produced by using the set of DEM analysis tools developed by Rigon et al. (2006) and using the Open Source JGrass GIS software (http://www.jgrass.org). The model PeakFlow is freely available for download under GPL 3.0 license as part of the GIS JGrass (where it is coded as a OpenMI 1.4 component) and in the JGrasstools (http://www.jgrasstools.org) coded as a OMS3 component.

Edited by: F. Laio

\section{References}

Barling, R. D., Moore, I. D., and Grayson, R. B.: A quasi-dynamic wetness index for characterise the spatial distribution of zones of surface saturation and soil-water content, Water Resour. Res., 30, 1029-1044, 1994.

Bell, F. C.: Generalized rainfall duration-frequency relationships, J. Hydraul. Eng., 95(HY1), 311-327, 1969.

Beven, K. J. and Kirkby, M. J.: A physically-based variable contributing area model of basin hydrology, Hydrol. Sci. Bull., 24, 43-69, 1979.

Beven, K. J.: Rainfall-Runoff Modelling: the Primer, Wiley, Chichester, 360 pp., 2001.

Beven, K. J. and Wood, E. F.: Flow routing and the hydrological response of channel networks, in: Channel Network Hydrology, edited by: Beven, K. J. and Kirkby, M. J., Wiley, Chichester, Chap. 5., 1993.

Botter, G. and Rinaldo, A.: Scale effect on geomorphologic and kinematic dispersion, Water Resour. Res., 39(10), 1286, doi:10.1029/2003WR002154, 2003.

Brutsaert, W.: Hydrology: an introduction, Cambridge university Press, Cambridge, UK, 2005.

Burlando, P. and Rosso, R.: Scaling and multiscaling DepthDuration-Frequency curves of storm precipitation, J. Hydrol., 187(1-2), 45-64, 1996.

Chow, V. T., Maidment, D. R., Mays, L. W.: Applied Hydrology, McGraw-Hill, 1988.

Da Ross, D. and Borga, M.: Use of digital elevation model data for the derivation of the geomorphological instantaneous unit hydrograph, Hydrol. Process., 11, 13-33, 1997.

Doodge, J. C. I.: The rational method for estimating flood peaks, Engineering, 184, 311-313, 374-377, 1957.

Doodge, J. C. I.: Linear theory of hydrologic systems, EGU reprints series, Katlenburg-Lindau, Germany, 1, 2003.

D'Odorico, P. and Rigon, R.: Hillslope and channel contributions to the hydrologic response, Water Resour. Res., 39(5), 1113-1121, doi:10.1029/2002WR001708, 2003.

D’Odorico, P., Fagherazzi, S., and Rigon, R.: Potential for landsliding: dependence on hyetograph characteristics, J. Geophys. Res.-Earth, 110, F01007, doi:10.1029/2004JF000127, 2005.

Fiorentino, M., Rossi, F. , and Villani, P.: Effect of the basin geomorphoclimatic characteristics on the mean annual flood reduction curve, in Proceedings of the IASTED International Conference, Modeling and Simulation, pp. 17771784, Pittsburgh, Pa., 1987.

Franchini, M. and O'Connell, P. E.: An analysis of the dynamic component of the geomorphologic instantaneous unit hydrograph, J. Hydrol., 175(1-4), 407-428, 1996.

Gupta, V. J. and Mesa, O. J.: Runoff generation and the hydrologic response via channel network geomorphology - recent progress and open problems, J. Hydrol., 102, 3-28, 1988.

Gupta, V. J., Waymire, E., and Wang, C. T.: A representation of an IUH from geomorphology, Water Resour. Res., 16, 885-892, 1980.

Henderson, F. M.: Some Properties of the Unit Hydrograph, J. Geophys. Res., 68(16), 4785-4794, 1963.

Hershfield, D. M.: Rainfall frequency atlas of the United States for durations from 30 minutes to 24 hours and return periods from 1 to 100 years, Technical Paper No. 40, superseded by Hydrometeorological Report No. 35, US Department of Commerce, Na- 
tional Weather Service, Silver Springs, MD, 1961.

Kirkby, M.: A runoff simulation model based on hillslope topography, in: Scale problem in Hydrology, edited by: Gupta, V. K., Rodriguez-Iturbe, I., and Wood, E., and Reidel, D., Dordrecht, 1986.

Iacobellis, V. and Fiorentino, M.: Derived distribution of floods based on the concept of partial area coverage with a climatic appeal, Wat. Resour. Res., 36, 469-482, 2000.

Mesa, O. J. and Mifflin, E. R.: On the relative role of hillslope and network geometry in hydrologic response, in: Scale problem in Hydrology, edited by: Gupta, V. K., Rodriguez-Iturbe, I., and Wood, E., and Reidel, D., Dordrecht, 1986.

Mulvaney, T. J.: On the use of self-registering rain and flood gauges in making observation of the relations of rainfall and flood discharges in a given catchment, Proceedings of the Institution of Civil Engineers of Ireland, 4, 19-31, 1851.

Meynink, W. J. C. and Cordery, I.: Critical duration of rainfall for Flood estimation, Water Resour. Res., 12(6), 1209-1214, 1976.

Naden, P. S.: Spatial variability in flood estimation for large catchments: the exploitation of channel network structure, Hydrolog. Sci. J., 37, 53-71, 1992.

Naden, P., Broadhurst, P., Tauveron, N., and Walker, A.: River routing at the continental scale: use of globally-available data and an a priori method of parameter estimation, Hydrol. Earth Syst. Sci., 3, 109-123, doi:10.5194/hess-3-109-1999, 1999.

Nash, J. E.: The form of the instantaneous unit hydrograph, International Association of Science and Hydrology, 45(3), 114-121, 1957.

Rigon, R., Ghesla, E., Tiso, C. R., and Cozzini, A.: The Horton machine: a system for DEM analysis: the reference manual, Dipartimento di Ingegneria Civile ed Ambientale and CUDAM, http://www.ing.unitn.it/dica/eng/Quaderni/index.php, last access: 28 April 2011, 1-144, 2006.

Rinaldo, A. and Rodriguez-Iturbe, I.: Geomorphological theory of the hydrological response, Hydrol. Process., 10(6), 803-829, 1996.

Rinaldo, A., Marani, A., and Rigon, R.: Geomorphological dispersion, Water Resour. Res., 27(4), 513-525, 1991.

Rinaldo, A., Vogel, G. K., Rigon, R., and Rodriguez-Iturbe, I.: Can one gauge the shape of a basin?, Water Resour. Res., 31(4), 1119-1127, 1995.
Robinson, J. S. and Sivapalan, M.: An investigation into the physical causes of scaling and heterogeneity of regional flood frequency, Water Resour. Res., 33(5), 1045-1059, 1997.

Rodriguez-Iturbe, I. and Valdes, J. B.: The geomorphic structure of hydrologic response, Water Resour. Res., 18(4), 877-886, 1979.

Ross, C. N.: The calculation of flood discharge by the use of time contour plan isochrones, Transaction of the Institute of Engineers, Australia, 2, 85-95, 1921.

Saco, P. M. and Kumar, P.: Kinematic dispersion in stream networks, Part 1: Coupling hydraulic and network geometry, Water Resour. Res., 38(11), 1244, doi:10.1029/2001WR000695, $2002 a$.

Saco, P. M. and Kumar, P.: Kinematic dispersion in stream networks, Part 2: Scale issues and self-similar network organization, Water Resour. Res., 38(11), 1245, doi:10.1029/2001WR000694, 2002b.

Sherman, L. K.: Streamflow from rainfall by the unit-graph method, Engineering News-Record, 108, 501-505, 1932.

Shreve, R. L.: Stream lengths and basin areas in topologically random channel networks, J. Geol., 77, 397-414, 1969.

Sivapalan, M., Beven, K. J., and Wood, E. F.: On the hydrologic similarity, 2. A scaled model of storm runoff production, Water Resour. Res., 23(12), 2266-2278, 1987.

Snell, J. D. and Sivapalan, M.: On geomorphological dispersion in natural catchments and the geomorphological unit hydrograph, Water Resour. Res., (30(7), 2311-2324, doi:10.1029/94WR00537, 1994.

Wood, E. F., Sivapalan, M., and Beven, K.: Similarity in small catchments storm response, Rev. Geophys., 28, 1-18, 1990.

Woods, R. A. and Sivapalan, M.: A connection between topographically driven runoff generation and channel network structure, Water Resour. Res., 33(12), 2939-2950, 1997.

Woods, R. A. and Sivapalan, M.: A synthesis of space-time variability in storm response: rainfall, runoff generation and routing, Water Resour. Res., 35(8), 2469-2485, 1999.

Yang, D., Herath, S., and Musiake, K.: A hillslope-based hydrological model using catchment area and width functions, Hydrolog. Sci. J., 1, 49-65, 2002. 